\title{
Sick Surgeon: Problem and the panacea!
}

\author{
Bikal Ghimire \\ Department of GI and General Surgery, Maharjgunj Medical Campus, Instute of Medicine, Tribhucan University. \\ Editor in Chief, JSSN \\ Email: drbikalghimire@iom.edu.np
}

Gautam Buddha has rightly said 'To keep the body in good health is a duty... otherwise we shall not be able to keep our mind strong and clear'. We need clear minds as a clinician and more so as surgeon to plan the course of treatment and to physically execute it. However, apart from clear minds a surgeon should also be physically capable to withstand strenuous activities for long periods of time. Daily exertion for prolog periods for surgeons leads to poor quality of life especially in our subcontinent where health institutions and the government do not prioritize the health of clinicians.

\section{The problem}

The surgeon faces a myriad of health issues related to musculoskeletal disorders, cardiovascular diseases, sleep deprivation, burn out and mental health issues apart from the risks involved in the operation theater.

A review of ill health in 574 doctors associated with NHS revealed skin related disease, psychiatric illness and musculoskeletal diseases and alcohol and drug abuse to be very common. ${ }^{1}$

With the advent of laparoscopy, focus has always been on patient safely and cost but compared with open surgery, laparoscopic surgery imposes greater ergonomic constraints on surgeons. There is $73 \%$ to $88 \%$ prevalence of physical complaints among laparoscopic surgeons, which is greater than in the general working population. Prevalence of musculoskeletal disorder (MDS) has been observed to be 73 to $88 \%$ among specialists in minimal invasive surgery where as in general occupational population the prevalence of backache was $24.7 \%$, muscular pain $22.8 \%$, and neck and shoulder pain $23 \%$. Symptoms associated with these MSDs mainly include fatigue, pain, stiffness, and numbness and such symptoms can affect task accuracy. ${ }^{2,3} \mathrm{~A}$ surgeon in pain may not be able to give the best possible treatment to their patients. In a review of various approaches to prostatectomy, 25\% surgeons complained that musculoskeletal pain considerations impacted their choice of operative approach and 32\% considered open most painful followed by laparoscopic and robotic to be the least. ${ }^{4}$

Apart from the strain of physical exertion, surgeons are exposed to certain occupational hazards like cuts, needle pricks and infections. On average, surgeons report a rate of approximately 11 injuries over a 3 -year time period.

Infections due to the exposure to blood, body fluids or tissue specimens possibly leading to blood-borne diseases such as HIV, Hepatitis B and Hepatitis C and use of CO2 laser risk infection with HPV (human papilloma virus). In the US, of the four million health care workers at risk for infection with blood borne pathogens, $25 \%$ are surgeons. ${ }^{5}$

Though HIV, hepatitis B virus (HBV) and hepatitis C virus (HCV) pose the highest risk of morbidity and mortality, there are over 20 blood borne pathogens identified as transmissible through sharps injuries. 4B Though HIV is dreaded; the risk of seroconversion following exposure to HIV from a needle-stick injury is approximately $0.3 \%$, and even lower when the exposure is confined to mucous membrane or cutaneous exposures. ${ }^{6}$

It supports the need to address the physical health issues of surgeons with eagerness. ${ }^{7}$

Apart from physical health, mental health is also an important issue. Since time immemorial, surgeons have always been stereotyped as brash, arrogant with little in the way of human compassion. For many, this may be a way of shielding away from the pain they suffer so that they can operate with the level of confidence that is required for each and every patient and for a few it may be just what they are. It has been rightly said that each surgeon carries within him burden of a graveyard. ("Every surgeoncarries within himself a small cemetery, where from time to time he goes to pray - a place of bitterness and regret, where he must look for an explanation for his failures. 'René Leriche, La philosophie de la chirurgie, 1951")

The sheer mental stress imposed trying to save a dying 
patient and the inevitable failures can be depressing. All clinicians are at risk of developing mental health problems but surgeons have been found to be the ones least likely to seek help. ${ }^{8}$

In the UK where the quality of life of surgeons is lot better than most developing countries, 10 to $20 \%$ become depressed at some point in their carrier. ${ }^{9}$ Suicide is a common issue among doctors, and relative to the general population female doctors have a 3.7 -fold to 4.5 -fold increased risk of death from suicide, and male doctors have a 1.5 -fold to 3.8 -fold increased risk. ${ }^{10,}{ }^{11}$ In a review of doctors presenting to the Practitioner Health Program (PHP), a confidential London based health service for doctors and dentists, it was observed that surgeons had myriads of health issues mainly 55\% depression and anxiety, $30 \%$ complex mental health issues and $16 \%$ with addiction.

Though this was lower than that observed with other health professionals it could be because surgeons are tailored to cope better with stress due to their rigorous training or they tend to underreport due to the stigmata attached that might risk their career. ${ }^{12}$

Violence against medical professionals is a global phenomenon as it involves emotional issues for the patients and their families and surgeons are more prone to suffer from it. There has been increase in such incidences in resent years with a survey amongst doctors by Indian Medical Association, reporting $75 \%$ observing such incidences at work. ${ }^{13}$ This adds to the level of stress associated with the occupation.

\section{The panacea!}

The Practitioner Health Program (PHP) is a confidential London based health service for doctors and dentists. Practitioners presenting to the service have considerable, often severe, mental health problems, similar to patients who present to NHS mental health services.6 Most developing countries lack a system to take care of health workers by assessing the problems and working towards the solution. It is high time various societies and the government work together to have a system to address the issue before it is too late.

Burnout has been characterized by, overwhelming physical and emotional exhaustion; feelings of cynicism and detachment from the job, a sense of ineffectiveness and lack of accomplishment; over identification with work to the exclusion of other activities and irritability and hyper vigilance. It is imperative that all surgeons are aware of the features and seek help at the earliest. ${ }^{14}$

A systematic literature review of PubMed, Embase and Cochrane Library in spring 2015 for comparative data on surgeons' physical workload with robotic-assisted laparoscopy and conventional laparoscopy which involved 2685 records were screened and 15 articles suggested that robotic-assisted laparoscopy is less strenuous compared with conventional laparoscopy. However, the widespread use of Robotics is limited by the high cost involved and availability especially in our subcontinent. Prevention of spread of sharp injuries and transmission of infection during surgeries requires following universal precaution and using safety guidelines. However, the compliance amongst surgeons is less, most blaming lack of safe devices, urgency of the procedure and lack of dexterity and blunted sensation associated with double gloving and other safety systems though studies have not provided any evidence to support it. ${ }^{15}$

In the American College of Surgeons (ACS) report, "Being well and staying competent: Challenges for the Surgeon" created in 2012, acknowledges that healthcare systems and hospitals don't have an incentive to limit surgeons' working hours and the burnout to be reversible and addresses methods to tackle burnout. ${ }^{16}$ They advice for promoting a culture of medicine that values work-life balance, promote the "just culture" paradigm during training and most importantly, give ourselves permission to be sick and to accept good medical care. We should also nurture the religious/spiritual aspects of ourselves and get involved in non-patient care activities (e.g., research, education, administration).

In the US, work-hour limitations have been implemented by the 'Accreditation Council for Graduate Medical Education' (ACGME) in July 2003 in order to minimize fatigue related medical adverse events. ${ }^{17}$ In Nepal, the remuneration for doctors is one of the lowest amongst other developing countries. Hence, doctors tend to work for extended hours and are exposed to mental and physical exhaustion, which is seen more commonly in surgeons. With the need to keep updated with rapidly progressing advances in medicine, doctors are in the need of attending Continuing medical education (CME) programs, workshops and courses. The government is also working on making these activities mandatory. In this context, health professionals should be allocated a 5 days work day with a day dedicated to perusing these activities so that their social life is not compromised. 


\section{Conclusion}

To safe guard the health of doctors, we need to study their present status including physical and mental health, timing of work hours and the morbidity and mortality in the community. Societies should work to promote health and working conditions of the clinicians and lobby the legislature to make rules and regulation to safe guard it. A healthy clinician will only be capable of delivering quality care to their patients that translates into improved health care in the country.

\section{References}

1. Ananth Vijendren, Matthew Yung, Jose Sanchez. The ill surgeon: a review of common work-related health problems amongst UK surgeons. Langenbeck's Archives of Surgery December 2014, Volume 399, Issue 8, pp 967-979

2 Huysmans MA, Hoozemans MJ, van der Beek AJ, et al. Fatigue effects on tracking performance and muscle activity. J Electromyogr Kinesiol. 2008;18:410-419.

3. Huysmans MA, Hoozemans MJ, van der Beek AJ, et al. Position sense acuity of the upper extremity and tracking performance in subjects with non-specific neck and upper extremity pain and healthy controls. J Rehabil Med. 2010;42:876-883.

4. Bagrodia A, Raman JD. Ergonomics considerations of radical prostatectomy: physician perspective of open, laparoscopic, and robot-assisted techniques. J Endourol. 2009;23:627-633.

5. Jennifer F. Waljee, MD, MS1, Sunitha Malay Sharps Injuries: the Risks and Relevance to Plastic Surgeons. Plast Reconstr Surg. 2013 Apr; 131(4): 784-791.

6. Zanni GR, Wick JY. Preventing needle stick injuries. Consult Pharm. 2007; 22:400-402. 4-6, 9. [PubMed: 17658957]

7. Chantal C. J. Alleblas, Anne Marie de Man, Lukas van den Haak. Prevalence of Musculoskeletal Disorders Among Surgeon; Performing Minimally Invasive Surgery. Annals of Surgery Volume XX, Number XX, Month 2017
8. Clare Gerada, Richard Jones. Surgeons and mental illness: a hidden problem? BMJ 2014; 348 doi: https:// doi.org/10.1136/bmj.g2764.

9. Brooks S, Gerada C, Chalder T. Review of literature on the mental health of doctors: are specialist services needed? J Mental Health 2011;1-11:I.

10. Frank E, Biola H, Burnett CA. Mortality rates and causes among US physicians. Am J Prev Med 2000;19:155-9.

11. Lindeman S, Laara E, Hakko H, Lonnqvist J. A systematic review on gender-specific suicide mortality in medical doctors. Br J Psychiatry1996;168:274-9.

12 Gerada, C. Surgeons and mental illness: a hidden problem? BMJ 2014;348:g2764

13. [Last accessed on 2018 Jan 10]. Available from: http://www.timesofindia.indiatimes.com/ india/75-percent- of-doctors-have-been-attacked- atwork-by-disgruntledattendants-study-says/ articleshow $/ 49533759 \mathrm{cms}$.

14. Kearney MK. Self-Care of Physicians Caring for Patients at the End Of Life. JAMA. 2009; 301:11551164).

15. Fry DE, Harris WE, Kohnke EN, Twomey CL. Influence of double-gloving on manual dexterity and tactile sensation of surgeons. Journal of the American College of Surgeons. 2010; 210:325-330. [PubMed: 20193896]

16. Pape H C, Pfeifer R, Patient Safety in Surgery 2009, 3:3 Restricted duty hours for surgeons and impact on residents quality of life, education, and patient care: a literature review, BMC, doi:10.1186/1754-9493-3-3

17. Governor's Committee on Physician Competency and Health, Being well and staying competent: Challenges for the Surgeon; 2013 (accessed on $2^{\text {nd }}$ dec, 2018 at https://www.facs.org/ /media/files/member\%20 services/being_well_and_staying_competent.ashx. ) 